\title{
Utilization prospects for coal mine methane (CMM) in Kuzbass
}

\author{
Oleg Tailakov ${ }^{1,2 *}$, Denis Zastrelov ${ }^{1}$, Vitaliy Tailakov ${ }^{3}$, Maxim Makeev ${ }^{1}$, Peet Soot $^{4}$ \\ ${ }^{1}$ Institute of Coal of Federal Research Center SB RAS, 650065, Kemerovo, Leningradsky ave., 10, \\ Russia \\ ${ }^{2}$ T.F. Gorbachev Kuzbass State Technical University, 650000, Kemerovo, Vesennya str., 28, Russia \\ ${ }^{3}$ JSC "Uglemetan Service", 650000, Kemerovo, Tereshkova str., 40, Russia \\ ${ }^{4}$ CMM Energy LLC, 333 S. State St. \# V-133, 97034, Lake Oswego, Oregon USA
}

\begin{abstract}
Coal mine methane (CMM) is a considerable, relatively unused, resource in Russia. With the second largest proven coal reserves in the world, behind the USA, Russia has a tremendous coalbed methane (CBM) resource. The coal mine methane (CMM) emissions which are created from the CBM resource by way of coal mining yield a significant fraction of the anthropogenic greenhouse gas emissions in the country. Developing CMM utilization projects will mitigate at least some of these emissions. Having evaluated the CMM resources at various underground coal mines in Kuzbass, it has been determined that it is economically viable to apply a variety of CMM utilization technologies in Russia. CMM use for electricity production was found to be quite capital intensive. Although economically viable, this option was the least attractive of the four technologies which were considered. Thermal energy production from boilers and delivering liquefied CMM at vehicle fueling stations were of intermediate potential. The most attractive option is the fueling of vehicles with compressed CMM. This required the lowest capital investment and had the highest paybacks, including a very rapid $2 \frac{1}{2}$ year payback.
\end{abstract}

\section{Introduction}

Russia has the second largest proven reserves of coal in the world, behind only the USA (BP, 2014). However, in coal production they are number six (6) in the world, having produced 165 million tons of coal in 2013. The coal reserves provide a large source for coalbed methane (CBM) and the production still yields a significant amount of coal mine methane (CMM) from underground coal mines. This CMM is the source of a significant fraction of the anthropogenic greenhouse gas emissions in this country. Developing CMM utilization projects will mitigate at least some of these emissions.

\footnotetext{
* Corresponding author: oleg2579@gmail.com
} 
The Kuznetsk Basin (also known as Kuzbass) is not the largest coal basin in Russia, but is the location of the most underground coal mine production. Hence, it is the source of most of the CMM production in Russia. The CBM resource in Kuzbass is 13 trillion $\mathrm{m}^{3}$ (Gazprom, 2014). About 20\% of these CBM resources are at mineable depths down to 600 meters. Another $40 \%$ are at depths down to 1200 meters, with the balance of this defined resource found within 1800 meters of the surface. There are likely additional resources in deeper horizons, but those have not been defined. The rest of Russia, outside Kuzbass, holds much more CBM (reportedly over 70 trillion $\mathrm{m}^{3}$ ), but it is not located near major population centers like Kuzbass and has not been explored as much. The Kuzbass CBM resource is larger, 13.1 trillion $\mathrm{m}^{3}$ vs. 8.4 trillion $\mathrm{m}^{3}$ than the resource in the San Juan Basin in the USA (Potential Gas Committee). And, the San Juan Basin is the source of the largest production of CBM in the USA. The low permeability of the coal in Kuzbass will not allow as prolific CBM production from Kuzbass as from the San Juan, but the resource is still there.

This article considers the CMM resources in Kuzbass, taking into account the various methane sources in underground coal mines. Those include the coal seam being mined as well as the coal seams overlying and underlying the active seam during and after mining. Four technologies were considered for the utilization of the CMM:

- Electric power generation;

- Thermal energy production in boilers;

- Fueling of vehicles with compressed CMM; and

- Fueling of vehicles with liquefied CMM.

The economic viability of each of these options were evaluated with an economic analysis which calculated net present value (NPV), internal rate of return (IRR), investment payback period in years and profitability index (PI).

It views evaluation approaches of coalbed methane resources developed in the area, taking into account the peculiarities of its supply from coal seams during and after mining. It was given an estimation of economic efficiency of methane utilization in generating stations, boilers and gas stations, fueled by compressed and liquefied coal mine methane.

\section{CMM Resources}

The coal mines in Kuzbass yield the CBM in the coal in the various forms of coal mine methane (CMM): drained gas, ventilation air methane (VAM), and abandoned mine methane (AMM). The drained gas is often the only form of coal mine methane that is considered by developers, but the other forms of CMM also exist and are a potential resource for utilization.

Kuzbass coal mine degasification systems bring 100-200 million $\mathrm{m}^{3}$ of drained methane to the surface annually. This methane comprises up to $80 \%$ of the methane/air mixture that is produced. One can use this methane/air mixture in a variety of applications, including production of electricity and/or heat, for motor fuel and for chemical products. The use of degassing methane in these volumes, for example, would allow the production of 30-60 MW of electricity. To evaluate the possibility and effectiveness of developing CMM projects, a complex approach was considered, which consisted of assessing the CMM resources and performing an economic analysis of alternative utilization options.

Mining experience at Kuzbass coal mines show that degassing boreholes drilled from the surface into the goaf ("gob" in American terminology) are the most stable sources of gas with the required concentration. According to applicable regulations, the methane cannot be less than $25 \%$ of the drained gas for transportation. 
The goaf is that zone which is formed from the collapse of the strata overlying the coal when the mined seam has been extracted with the longwall mining machine. Since this zone is not isolated from the active mining area, the mine is ventilated in such a manner as to minimize the movement of the methane from the goaf to the active area and degassing boreholes are drilled into the goaf from the surface.

In the underground coal mines, the goaf methane consists of methane entering that zone during the unloading of the coal seam massif and which has migrated into that zone from the underlying and overlying coal seams, and from the remaining coal mass formed from remaining broken coal pillars. Given this mechanism, it is important to begin the understanding of the CMM resource by studying the formation of the goaf. In general, the amount of coal mass in the goaf is described by the mathematical formula in Equation 1.

$$
V_{i}^{\text {seam }}=\sum_{j=1}^{n} \iint_{s_{j}} m(x, y) d x d y,
$$

where $j=\overline{1, n} ; i=\overline{1, k} ; n$ - number of pillars in the $i$-th seam; $k$-number of coal seams; $m(x, y)$ - thickness of the $i$-th coal seam.

Figure 1 shows a 3-D distribution of the density of methane resources in one of the Kuzbass coal mines within the developed coal seam.

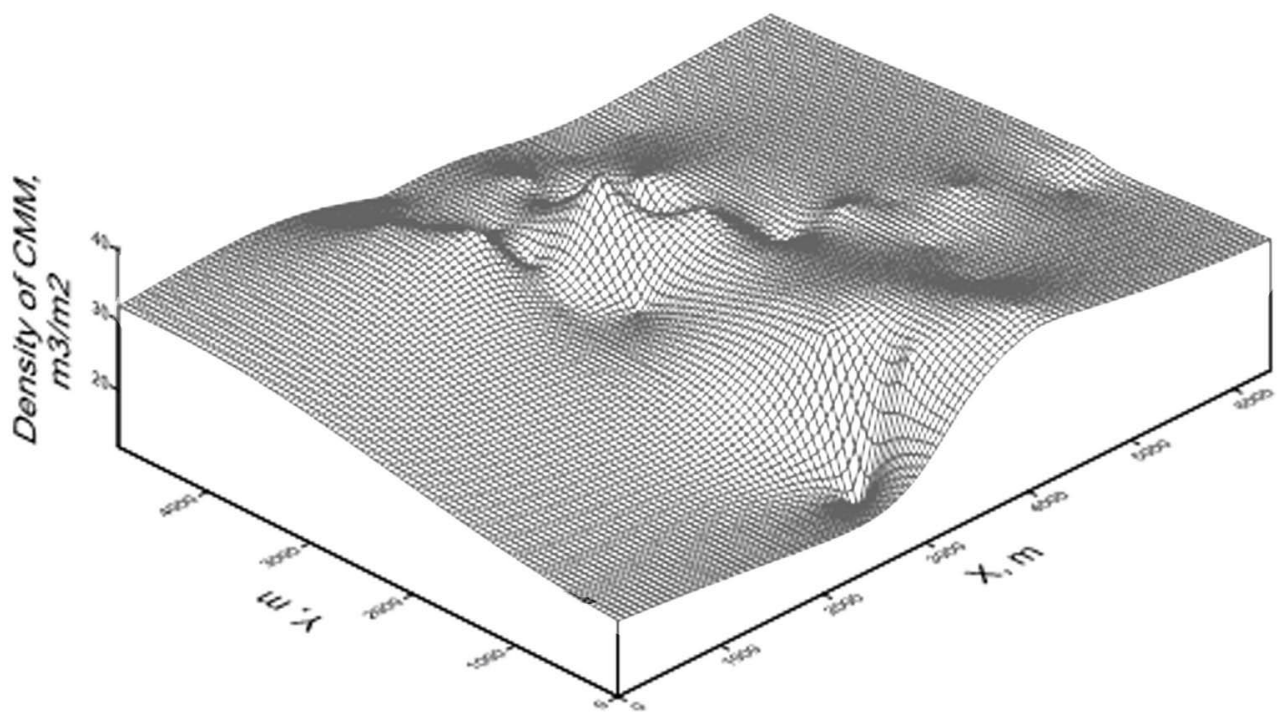

Fig. 1. 3-D representation of the density of coalbed methane resources in a Kuzbass underground mine

When drilling boreholes in the dome of the goaf, the concentration of methane-air mixture is achieved, sufficient for its use as efficient fuel.

Having information on the potential volume of CMM in these man-made reservoirs (goafs), which is based on data regarding methane in the goaf, provides the basis for evaluating the economic viability of CMM utilization projects - which is described below. 


\section{CMM Utilization Options}

Technologically, the most effective options for methane utilization are its use in generating stations, boilers, and gas stations working on compressed and liquefied CMM. Several projects on CMM utilization were fulfilled in Kuzbass. For example, installation of the modular boiler station of 0.7 MW capacity for thermal power generation at the Krasnogorskaya mine in Prokopyevsk; commissioning the gas generating unit of 0.9 MW capacity for electric power generation at the Kirova mine in Leninsk-Kuznetsky. Also, the project of coalmine methane utilization in power generator with $0.4 \mathrm{MW}$ electrical capacity is implemented on the Komsomolets mine. The technology of simultaneously use of two sources of air-methane: low (less than 3.5\%) and high (over 25\%) concentration of methane was successfully tested (Tailakov et al., 2004, Tailakov et al., 2014, Backhaus et al., 2009).

\section{Economic Analysis}

The main factors affecting the economic viability of CMM utilization projects are technological, environmental (the reduction of greenhouse gases in the atmosphere), social (the creation of additional jobs), financial, and marketing. If there is an increase in energy prices the investment attractiveness of such projects will also increase. Income sources of such methane projects are the revenue from selling the generated electrical and thermal energy, the savings on payments to the government for methane emissions into the atmosphere, and/or the savings over traditional fuels because of the use of CMM as a fuel for vehicles. Capital costs of the methane utilization project have many elements, including the following:

- defining the costs for development of the concept and technical and economic substantiation of the project (typically referred to as the front-end engineering and design FEED);

- project documentation, examination and approval of the project with the state regulatory agencies, the acquisition of basic and auxiliary equipment for methane utilization, area preparation, construction of foundations, pipelines, installation of valves, transformer station (typically referred to as the engineering, procurement and construction EPC), and commissioning activities.

The amount of investment required for the construction of a power generating station (IC engines) with a total power capacity of $30 \mathrm{MW}$ is estimated at 1174 million rubles.

Economic analysis of such projects shows that the amortization of CMM power generating station investments are the largest component of operating costs and estimated as $81 \%$ from the overall cost of the project while the next largest component is materials estimated as up to $14.5 \%$ from the overall cost (see Fig. 2).

This confirms the high capital intensity of the power generating option from among the various CMM utilization technologies.

The same applies to CMM utilization in gas boilers, where the amortization charges are again the largest element of operating costs - at $76.6 \%$.

And for vehicle fueling stations supplying liquefied methane amortization charges in the proportion of $76.2 \%$ of the operating costs are the largest single cost element. This technology option has the materials and components comprising $20.6 \%$ of operating costs, which is the largest share for this cost element of any of the evaluated CMM utilization technologies. This latter point is explained by the high costs of maintenance of complex technological equipment for the liquefaction of CMM. The power output of vehicle fueling stations supplying liquefied methane is 10.4 million liters per year. 

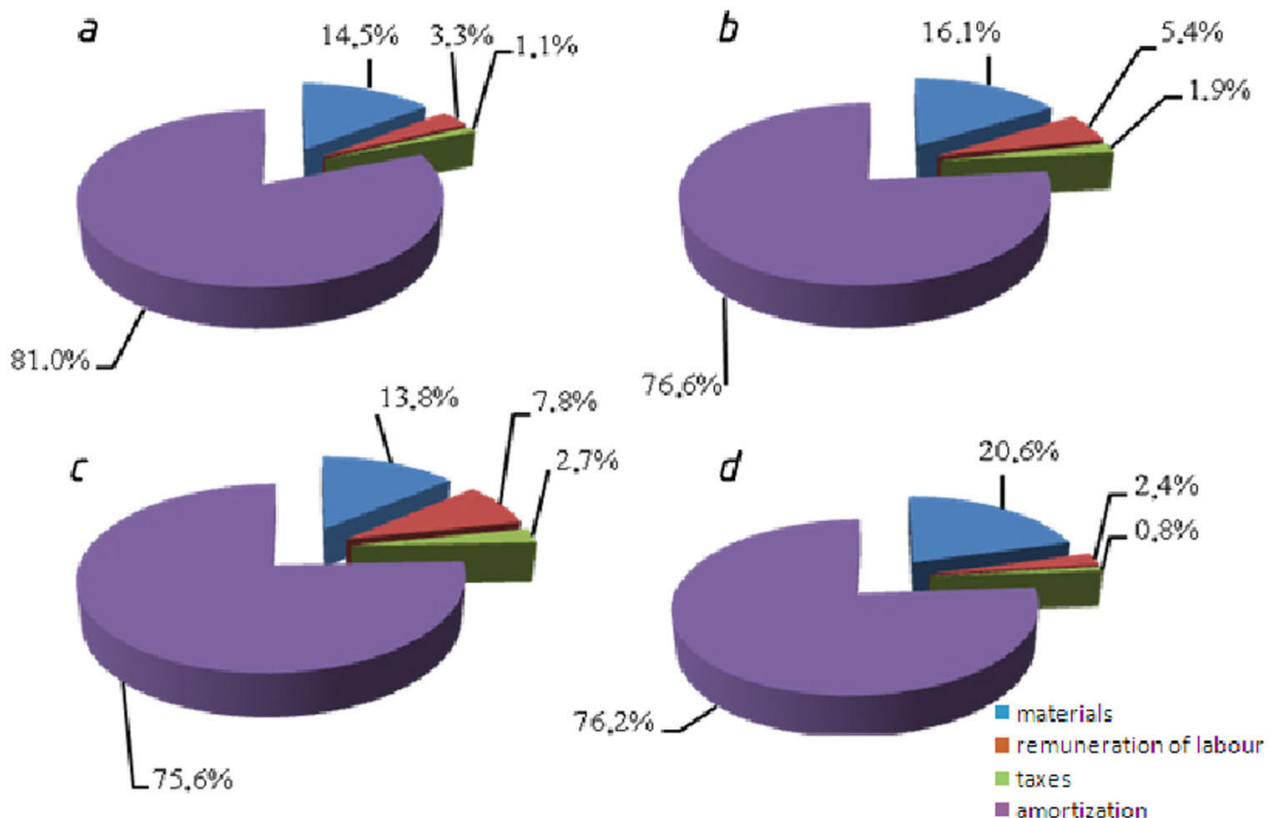

Fig. 2. The structure of the operating costs for CMM utilization projects: a) - $30 \mathrm{MW}$ power generating station, b) - $30 \mathrm{MW}$ gas boiler station, c) - gas station on compressed methane, and d) gas station on liquefied methane

The project of construction of gas stations, in which compressed mine methane is used to fuel vehicles, is characterized by the lowest amortization charges $(75.6 \%)$ in the structure of the operating costs of the project. The power output of vehicle fueling compressed CMM station is 1.971 million $\mathrm{m}^{3}$ of fuel per year.

Having defined the capital and operating costs, various economic analysis results were calculated for each of the technology options. The economic viability results are presented in the Table 1.

Table 1. Economic evaluation of the CMM utilization projects

\begin{tabular}{|l|c|c|}
\hline \multirow{2}{*}{\multicolumn{1}{|c|}{ Index }} & \multicolumn{2}{c|}{ Index Value } \\
\cline { 2 - 3 } & Generating Station (30 MW) & Gas Boiler (30 MW) \\
\hline Investment costs (mln RUR) & 1174 & 284 \\
\hline Payback period & 3.9 & 2.8 \\
\hline $\begin{array}{l}\text { Net present value (NPV) for 5 years } \\
\text { (mln RUR) }\end{array}$ & 267 & 187 \\
\hline IRR (\%) & 8.6 & 21.8 \\
\hline Profitability Index (PI) & 1.23 & 1.66 \\
\hline
\end{tabular}

Table 2. Economic viability evaluation for $\mathrm{CMM}$ utilization for compressed and liquefied methane as a fuel for vehicles

\begin{tabular}{|l|c|c|}
\hline \multirow{2}{*}{\multicolumn{1}{|c|}{ Index }} & \multicolumn{2}{|c|}{ Index Value } \\
\cline { 2 - 3 } & $\begin{array}{c}\text { Compressed Natural Gas } \\
\text { (CNG) Station }\end{array}$ & $\begin{array}{c}\text { Liquefied Natural Gas } \\
\text { (LNG) Station }\end{array}$ \\
\hline Investment costs (mln RUR) & 81 & 460 \\
\hline Payback period & 2.5 & 2.7 \\
\hline
\end{tabular}




\begin{tabular}{|l|c|c|}
\hline $\begin{array}{l}\text { Net present value (NPV) for 5 years } \\
\text { (mln RUR) }\end{array}$ & 67 & 326 \\
\hline IRR (\%) & 26.5 & 23.3 \\
\hline Profitability Index (PI) & 1.82 &., 71 \\
\hline
\end{tabular}

The CMM utilization project using a boiler is considerably more attractive for potential investors when compared to the construction of the gas power generator, since the payback period of a modular boiler is less (2.8 years vs. 3.9 years) and its implementation requires a significantly lower amount of investment (284 mln RUR compared to $1174 \mathrm{mln}$ RUR).

The project where gas stations provide compressed CMM as a fuel is much more attractive than gas stations that deliver liquefied CMM because the LNG stations would require over 5 times more capital expenditure (Table 2). The payback period of the project, involving the use of technology to compress the gas, is 2.5 year, with investment costs of $81 \mathrm{mln}$ RUR. Net present value over 5 years is 67 million rubles, the internal rate of return $-26.5 \%$, profitability of investments (PI) -1.82 .

\section{Conclusions}

Further development of the CMM utilization projects in Kuzbass will contribute to the rational use of energy resources that are suitable for thermal and electric energy production; will reduce greenhouse gas (methane) emissions into the atmosphere and create new job places. Also, the use of coal mine methane will increase the energy efficiency of coal enterprises. According to the produced economic analysis the project of converting the vehicles on fueling by the compressed CMM is the most attractive option for the CMM utilization in Kuzbass, but its implementation will require existence of the high concentrated methane (not less than $80 \% \mathrm{CH}_{4}$ in the air methane blend) source.

\section{References}

1. BP Statistical Review of World Energy, 2014.

2. Gazprom, 2014, Russian CBM Resources, http://www.gazprom.com/, internet site accessed 11/06/14.

3. Potential Gas Committee, 2006, Russian Forecasted CBM Resources.

4. O.V. Tailakov, D.V. Islamov, D.N. Zastrelov, V.O. Tailakov The 7th International Conference on Greenhouse Gas Control Technologies (Vancouver, Canada, 2004).

5. O.V. Tailakov, D.N. Zastrelov, E.A. Utkaev, A.I. Smyslov, A.N. Kormin, Taishan Academic Forum - Project on mine Disaster Prevention and Control, 450, 2014.

6. C. Backhaus, V.A. Bezpflyug, E.V. Mazanik, C. Hoppe, Coal, 11, 50 (2009). 